\title{
State of the Journal
}

Thomas J. Silhavy, a Editor in Chief, Journal of Bacteriology

aDepartment of Molecular Biology, Princeton University, Princeton, New Jersey, USA

T he Journal of Bacteriology (JB) is a prestigious periodical that publishes research articles that probe fundamental processes in bacteria, archaea, and their viruses and the molecular mechanisms by which they interact with each other and with their hosts and their environments. It has served the microbial community with distinction for more than 100 years. The high standards of the journal are maintained by a distinguished group of editors with collective expertise in wide-ranging research areas. I am pleased to note that Yves Brun, a leader in microbial cell biology, recently joined our ranks. Short career summaries for most of us can be found on the journal home page (http://jb.asm.org/).

As part of our 100th anniversary in 2016, we highlighted important papers that have been published in JB with a series of 48 Classic Spotlights, each written by an editor. These spotlights present brief summaries of papers that had lasting impact in the field. It is worth noting that the true significance of many of these papers was not realized until much later. We think these spotlights are particularly useful for both teachers and students. The entire collection of these spotlights can be found on the journal homepage.

JB publishes minireviews that include graphical summaries for teaching to help scientists keep up with fast moving fields. Recently, the editors have selected minireviews in three key areas, which have been collected and published as free, downloadable ebooks. These thematic collections are available at this website: http://jb.asm.org/ site/misc/JB_Special_Collections.xhtml?utm_source=CollectionAll\&utm_medium = email\&utm_campaign=JBCollections. I urge readers to take advantage of these terrific resources.

The biggest problem facing the journal is the decreased number of submissions that we have received in the last few years. In part, this is due to the ever-increasing number of new journals. A significant number of these new journals are published by for-profit companies, and because of incorrectly perceived issues of visibility and impact, many scientists choose to send their work to these journals. As a consequence, JB and society journals in general are suffering. I believe that there is no journal in the field of bacterial molecular biology that has a more qualified group of editors than we do. Send us your paper; I promise you will not be disappointed with the quality or speed of the review process.

In 2017 Richard Gourse and Piet de Boer reached the end of their second terms and retired as editors. During their decade of service, they worked tirelessly to maintain standards and help authors navigate the publishing process. Both will be missed.

A large number (438) of ad hoc reviewers assisted our review process last year, demonstrating a high degree of community support for the journal. These scientists are listed in volume 199, issue 24, at e00571-17. These reviewers, together with the editors and Editorial Board members, provided high-quality reviews with an average time to first decision of 27 days.

A number of our Editorial Board members deserve special recognition. In the last year, these scientists have reviewed at least seven manuscripts each with an average turnaround time of 16 days or less. Wholehearted thanks go to them all:
Accepted manuscript posted online 30 October 2017

Citation Silhavy TJ. 2018. State of the journal. J Bacteriol 200:e00635-17. https://doi.org/10 .1128/JB.00635-17.

Copyright $\odot 2017$ American Society for Microbiology. All Rights Reserved.

Address correspondence to tsilhavy@princeton.edu.

The views expressed in this Editorial do not necessarily reflect the views of the journal or of ASM. 
Birgit E. Alber, Ohio State University

Gladys Alexandre, University of Tennessee at Knoxville

Robert B. Bourret, University of North Carolina at Chapel Hill

Ciaran Condon, Institut de Biologie Physico-Chimique

Michael M. Cox, University of Wisconsin-Madison

Marie A. Elliot, McMaster University

Alain Filloux, Imperial College London

Susan Gottesman, National Cancer Institute

Brian K. Hammer, Georgia Tech

Daniel B. Kearns, Indiana University, Bloomington

Birgit E. Scharf, Virginia Tech

Eric V. Stabb, University of Georgia

Karen L. Visick, Loyola University Chicago

Cheng-Cai Zhang, Institute of Hydrobiology, Chinese Academy of Sciences

This year, eight new scientists were appointed to the Editorial Board to replace retiring members:

Melanie Barnett, Stanford University

Yana Bromberg, Rutgers University

Sarah Fortune, Ragon Institute of MGH, MIT, and Harvard

David Graham, Oak Ridge National Laboratory

Debbie Hinton, National Institutes of Health

Thomas Kehl-Fie, University of Illinois at Urbana-Champaign

Vince Lee, University of Maryland

Lyle Simmons, University of Michigan

Each of them brings special expertise to the journal, and speaking for all of the editors, I welcome them. 